\title{
LAS FALACIAS DE LA POSVERDAD: DESDE LA COMPLEJIDAD Y LA TRANSDISCIPLINARIEDAD
}

\author{
The Fallacies of the Post-Truth: \\ From the Complexity and the Transdisciplinarity \\ Julieta Haidar \\ Escuela Nacional de Antropología e Historia \\ jurucuyu@gmail.com
}

Resumen:

En este artículo, el objetivo nuclear es analizar la categoría de posverdad, partiendo de las condiciones de producción, circulación y recepción que permitieron su impacto y amplia difusión en los distintos campos cognitivos y en los medios masivos de comunicación. En segundo lugar, abordamos los problemas de la verdad en varios tipos de discursos y semióticas, ya que este tema siempre produce múltiples nudos gordianos. En tercer lugar, definimos la posverdad con sus principales características y la relacionamos con lo ético, lo político y otros campos.

\section{Palabras clave:}

Posverdad, ética, política, discurso, semiótica.

\begin{abstract}
:
In this article, the nuclear objective is to analyze the category of post-truth, starting from the conditions of production, circulation and reception that allowed its impact and its wide diffusion in the different cognitive fields and in the mass media of communication. Secondly, we address the problems of truth in various types of discourse and semiotics, since this topic always produces multiple gordian knots. Thirdly, we define the post-truth with its main characteristics and relate it to the ethical, the political, and other fields.
\end{abstract}

\section{Keywords:}

Post-truth, Ethics, Politics, Discourse, Semiotics. 


\section{INTRODUCCIÓN}

Uno de los desafíos y retos que enfrentamos al analizar el concepto de posverdad, se refiere al impacto que tuvo en los últimos años, principalmente en 2016, cuando ocurren los dos fenómenos que se catalogan emblemáticos en esta era: la campaña de Donald Trump y el fenómeno de BREXIT, en Inglaterra. No es de nuestro interés, porque ya ha sido muy tratado en toda la producción en torno a la posverdad, detenernos en el origen del concepto ni en sus distintos usos por distintos autores. Nuestro objetivo principal es analizar las condiciones de producción, circulación, recepción que posibilitaron su emergencia y permanencia, para lo cual son fundamentales los aportes de Foucault (1980) en el abordaje de los problemas de la verdad, que siempre este autor liga al ejercicio del poder. En este sentido, la verdad, la locura, la razón no son esencias, sino que están subordinadas a los regímenes del poder/saber que condicionan lo que es verdadero, lo que es la locura, lo que es la razón en las distintas épocas y culturas. Pero si nos distanciamos un poco de la propuesta foucaultiana, podemos plantear que los funcionamientos de la verdad, de la locura, de la razón no sólo están condicionados por el poder, ya que pueden ser tratados desde otros ángulos analíticos, en los cuales emerge el pensamiento crítico.

El concepto que estamos analizando no puede desligarse de la crisis de credibilidad general que existe en relación a lo político y a los medios masivos de comunicación clásicos, produciendo una paradoja que se genera con la extraña credibilidad en los medios de comunicación digitales, en los cuales la verdad está casi siempre ausente, aunque existan otros dedicados a denunciar la producción de estas burbujas de la posverdad y la mentira que envuelven el mundo contemporáneo con una fuerza hasta el momento indomable. Aunque la posverdad cono fenómeno socio-cultural-histórico-político-económico haya existido desde siempre ligada al ejercicio del poder, en estos momentos su emergencia adquiere nuevos y peligrosos matices por el impacto de las redes sociales en el mundo hiperconectado en que estamos, en donde se descentraliza el poder, para tornarlo ubicuo, difuso, confuso, sin límites, como son algunas características de lo digital. En otras palabras, la posverdad adquiere otros funcionamientos complejos, porque con la cultura digital, que abarca el ciberespacio, el cibertiempo, el cibernantropo, produce y reproduce la hiperrealidad en que vivimos.

El panorama que se abre es bastante complejo, al surgir la categoría de posverdad, que se relaciona con otras semejantes de fines del siglo pasado, como son el posmodernismo, el posestructuralismo, el posfuncionalismo, lo poscolonial, entre otras construcciones epistemológicas permeadas por la crisis cognitiva de fines del siglo XX. En el caso de la categoría que nos ocupa, se introduce el siempre denso problema de la verdad, que desde la complejidad y la transdisciplina cruza muchos campos cognitivos, como son la filosofía, la política, lo jurídico, lo histórico, lo social, lo económico, desde las ciencias humanas, y también desde las ciencias naturales, como la biología, la química, la física, la genética, las neurociencas; en las cuales los desarrollos cognitivos recurren a lo verdadero desde otras dimensiones. Insistimos en afirmar que las propuestas desde la epistemología de la complejidad y de la transdisciplinariedad, nos conducen a considerar los funcionamientos de esta 
categoría en diversos campos cognitivos, entre los cuales nos detenemos en algunos en particular.

En este sentido, debemos abordar una primera contradicción recursiva entre dos conceptos verdad<->posverdad, que en términos semánticos introduce problemas para su comprensión y análisis, tanto por la polisemia del concepto de verdad, como por la ambigüedad y las aristas del concepto de posverdad. Con este neologismo, avalado por el Diccionario de Oxford en 2016, nos enfrentamos con un problema severo al preguntarnos qué se esconde detrás de la posverdad, qué sentidos se disparan con el prefijo condensador de significados 'pos'. Las condiciones de posibilidad de los discursos, según Foucault (1980), explican la emergencia de la categoría para abordar los fenómenos de un nuevo tipo de credibilidad, relacionado con nuevos regímenes del poder/saber, subordinados a la voluntad de 'verdad'. En estas condiciones anteriores, los sujetos no se preocupan por conocer la verdad de los hechos socio-culturales-históricos-políticos-económicos porque están atrapados por mecanismos de persuasión fuertemente vinculados a lo emocional y a las redes digitales. Estas condiciones de producción, circulación, recepción, que propician la victoria de la posverdad sobre la verdad, integran dos problemáticas que se articulan: lo cognitivo-racional que cede su lugar a lo cognitivo-emocional en las subjetividades y las redes digitales que atrapan con violencia simbólica a los sujetos hiperconectados.

Con este fenómeno, surge la producción de una perversidad monstruosa, en la cual tantos los sujetos productores de la posverdad, como los sujetos receptores se integran a una teatralidad de la mentira, del simulacro, producida por los poderes hegemónicos. Estos explican el impacto y la fuerza de la categoría en todas las redes sociales, en las cuales la dominación ejercida por Estados Unidos y la Comunidad Europea siguen reproduciendo un pensamiento colonizado que invade el conocimiento, frente al cual hay que ejercer un pensamiento crítico desde la decolonialidad (Mignolo 2005, Rivera Cushicanqui 2010, Castro Gomez/Grosfoguel 2007). Este pensamiento tiene ya muchos avances, producciones que cruzan varios campos cognitivos, que Ilaman a reconstruir la historia de la filosofía, de las ciencias, de las culturas, de las religiones, de las artes desde otras miradas, ubicadas en otras trincheras para descubrir y plantear que la filosofía no estuvo solo en Grecia, para defender otras concepciones estéticas desde la 'aesthesis decolonial', temas muy bien abordados y argumentados por los autores antes mencionados. Desde la decolonialidad, no se puede aceptar la posverdad con los sentidos que está circulando, porque para América Latina, Asia o África no tiene pertinencia tal categoría, a pesar de su abrumadora circulación en este mundo globalizado.

De este modo, la posverdad a pesar de su impacto e influencia desde hace casi tres años, genera varias tensiones y conflictos, porque los medios digitales de largo alcance espaciotemporal, es decir, cronotópico (Bajtin 1989) logran el mayor grado de manipulación de los acontecimientos naturales, sociales, políticos, económicos, culturales, históricos, etc. En efecto, el desarrollo de las hiperconexiones de alta velocidad, de gran impacto entre los sujetos, constituyen una herramienta fundamental para que la verdad ceda lugar a la posverdad, sin ningún cuestionamiento, sin ningún pensamiento crítico. En otras palabras, las nuevas estrategias persuasivas utilizadas en los escenarios digitales logran cada vez mayor impacto, mayor eficacia 
y los sujetos quedan atrapados en las redes perversas de la alienación, del fetichismo de la consciencia. Con esta afirmación fuerte, pero cierta, la verdad queda obsoleta frente a toda la especulación y la manipulación llevada a su máxima potencia por la posverdad en las producciones semiótico-discursivas de los medios digitales y los horizontes quedan oscurecidos, nebulosos por la victoria de la hiperrealidad, de lo impredecible, de la incertidumbre, dimensiones que son analizadas por la complejidad y la trandisciplinariedad.

\section{LAS PRÁCTICAS SEMIÓTICO-DISCURSIVAS ENTRE LA VERDAD, LO VEROSÍMIL, LA MENTIRA, LA FALACIA, LA POSVERDAD}

En este apartado, surgen varias problemáticas que debemos seguir abordando desde la complejidad y la transdisciplina. Si partimos de la verdad, es necesario establecer una tipología de la misma, en la cual hay diversas controversias, porque los sentidos del concepto de verdad son polisémicos dependiendo de la perspectiva del campo desde el que se ubica: los tipos de verdad son la filosófica, la lógica, la ontológica, la epistemológica, la ética, la moral, la científica, la histórica, la absoluta, la relativa, la política, etc. En este trabajo, no podemos tratar a profundidad todas las problemáticas generadas por estos tipos de verdad, sin duda fascinantes y desafiantes, porque no es nuestro objetivo, sino sería motivo de otro ensayo.

Lo que queremos considerar son algunos aspectos pertinentes, que se relacionan con la presencia o la ausencia de la verdad en los distintos discursos y semióticas, ya que en los campos semiótico-discursivos del arte, de la religión, del mito no tiene pertinencia preguntarse por la verdad. En consecuencia, si en estas producciones semiótico-discursivas no tiene pertinencia preguntarse por la verdad, menos pertinente es preguntarse por la posverdad. El arte, la religión, el mito establecen sus criterios desde otros parámetros, otros soportes en donde no hay cabida para preguntarse por la verdad (Haidar 2006). Por otro lado, en el desarrollo de múltiples campos cognitivos, atravesados por la verdad, se han producido múltiples investigaciones en las cuales se discuten los criterios de verdad, de falsedad y su pertinencia, pero por los objetivos del presente artículo, nos detenemos con mayor profundidad en el otro lado de la verdad, en el lado oscuro de la posverdad, con todas sus características disfóricas.

En este espacio oscuro, surgen categorías opuestas en contradicción con la verdad que son la verosímilitud, la mentira, la falacia, la posverdad. Así como el campo semántico de lo que es la verdad presenta varias problemáticas, de igual manera en el campo semántico de las categorías opuestas a la verdad se generan innumerables debates que tratamos de manera breve para procurar deslindar el concepto de la posverdad, que emerge con pretensiones de ubicarse como una producción positiva sobre los sentidos de los acontecimientos naturales, sociales, políticos, históricos, culturales, económicos, ecológicos, etc.

En primer lugar, la verosímilitud se aplica mucho en el terreno del arte, cuando los analistas proponen que no tiene pertinencia preguntarse por la verdad, sino por la verosímilitud de una narrativa, por ejemplo. Esta afirmación introduce múltiples problemas cuando nos adentramos en los diversos tipos de narrativa literaria, pero también en las teatrales, en el cine, en las visuales, etc. Lo verosímil, lo que parece 
verdad, se complica más cuando tratamos las pinturas, el cine surrealistas que no resisten a la búsqueda de lo verosímil, lo que alcanza mayor densidad en las producciones digitales de grandes simulaciones, en las cuales lo que predomina es la hiperrealidad como simulacro total (Baudrillard 1978). Por lo anterior, frente a las innumerables producciones de la cultura digital, del ciberespacio, del cibertiempo, del ciberantropo no tiene mucha pertinencia la búsqueda de la verdad, ni de lo verosímil porque no permiten abordar analíticamente las pinturas y el cine 3D y 4D, además de muchos otros experimentos del mundo digital que nos subordina.

En segundo lugar, la mentira es la oposición total a la verdad, siendo inmportante señalar que hay grados distintos tanto en lo verdadero, como en la mentira. En el campo filosófico, esta oposición aparece como verdad-falsedad y los planteamientos son de otro orden, como los relacionados con lo verdadero y lo falso en relación a las premisas de los distintos tipos de silogismo y de los sofismas. A los distintos grados que existen en la verdad y la mentira, se relacionan los varios tipos de verdad, ya mencionados, y los varios tipos de mentira. Un grave problema es que la mentira es una presencia continua y constante en el ejercicio de los poderes dominantes, en los cuales entra el funcionamiento peculiar de la ideología (Haidar 2006), ligado a la alienación, al fetichismo de la conciencia (Haidar 1990). Debemos también añadir que hay varios tipos de poder como el político, el jurídico, el militar, el religioso, el de los medios masivos, el de género y los micro poderes (Foucault 1993) como el de los hospitales, de las cárceles, de todas las instituciones, porque en el funcionamiento de casi todos se recurre a la mentira. Podría parecer una afirmación severa, pero en la historia hay muy pocos ejemplos de ejercicio del poder que no recurren a la mentira para la dominación, lo que se explica por el uso necesario de la manipulación. De nuevo, es pertinente retomar a Foucault (1980), cuando propone que lo verdadero y lo falso no son esencias, sino obedecen a regímenes subordinados a la voluntad de verdad/ del saber que están articulados a los diversos poderes, aunque pueden existir funcionamientos que escapen al poder, como hemos señalado. La posverdad, por lo tanto, tiene que ver con la producción y reproducción de la mentira tanto en la dimensión macro, como en la dimensión micro.

En una relación especular con la verdad, los varios tipos de mentira que podemos mencionar son: mentira política, mentira histórica, mentira social, mentira económica, mentira científica, mentiras piadosas, promesas rotas, mentiras intencionadas, mentiras del autoengaño, rumores, exageración, plagio, mentiras compulsivas. Los ejemplos de mentiras, tanto en los escenarios públicos, como en los cotidianos, son innumerables, así como su presencia en las diversas producciones semiótico-discursivas. Un ejemplo de la mentira económica/ posverdad se encuentra en las categorías de países desarrollados y países en desarrollo, porque en estos últimos no existe ningún proceso de desarrollo, como en el caso de Haití y de tantos países en África y en América Latina, en donde lo que emerge son la pobreza y la extrema pobreza. Otro ejemplo histórico de posverdad que impone la Iglesia, fue el juicio a Galileo Galilei, cuando éste para salvarse de la hoguera tuvo que abjurar de su tesis astronómica heliocéntrica, totalmente verdadera. En su abjuración, tuvo que arrodillarse frente a los Inquisidores del siglo XVII, para afirmar públicamente que se había equivocado frente al poder oscurantista de la Iglesia, con la violencia instalada en los procesos inquisitoriales. 
En tercer lugar, están las falacias ligadas a la filosofía. Es Hamblin (1970), quien en el Siglo XX rescata las falacias de sus estigmas negativos, para proponer que no existen producciones semiótico-discursiva sin falacias, por lo que éstas son inevitables y propias del pensamiento cotidiano, del pensamiento informal (no de la lógica formal) (Cf. Van Eemeren y Grootendorst 1987), que se materializan en los discursos y en las semiosis. Los sujetos al no poder evitar las falacias se insertan en otros tipos de lógicas, que no son aristotélicas, como la informal, la cotidiana, la emocional que no obedecen a los silogismos, sino a los entimemas, juicios incompletos en donde no tiene pertinencia la verdad formal. Sin embargo, a nuestro juicio, el rescate de las falacias de sus matices negativos, no justifican las mentiras que tienen otros funcionamientos.

Nigro Moser (2017) introduce nuevas reflexiones interesantes sobre la posverdad, recurriendo a la dimensión retórica de las falacias, y siguiendo la clasificación de Perelman plantea los siguientes grupos: a) Falacias de evidencia: cuando algún dato es ocultado o manipulado para afirmar algo que no es cierto; b) Falacias de lenguaje: cuando con estrategias lingüísticas se busca distraer al adversario o confundirlo; c) Falacias de pseudoargumentos: en donde entran muchísimas falacias.

Las falacias más frecuentes en el discurso político, según Nigro y Blaquier (En: Nigro Moser 2017) son:

- Argumento dirigido contra el hombre, ad hominem: se trata de ofender a la persona y no de refutar sus argumentos.

- Apelación al pueblo, ad populum. Es el discurso del demagogo. Apela a los sentimientos, supersticiones, creencias básicas del pueblo para que se acepte su argumento.

- Generalizaciones. Se reconocen por el uso de términos como: "todos", "nadie", "siempre", "jamás". Se pretende afirmar que es de conocimiento público y general algo que solo se da en algún caso.

- Simplificación. La realidad es compleja. Para cada efecto, hay muchas causas. Incluso interviene el azar. Sostener que un hecho tiene un único responsable es, por lo menos, infantil.

- Falsa analogía. Se intenta comparar dos situaciones o casos que no se asemejan verdaderamente en la realidad. Se traslada un ejemplo de un contexto comunicativo a otro lo que le quita toda validez argumentativa.

Otro ejemplo de falacia, es el argumento desde el silencio: es una falacia porque se extrae una conclusión basada en el silencio o ausencia de evidencia. Ejemplo: "sé dónde es la fiesta, pero no te lo voy a decir / entonces no sabes dónde es la fiesta". Otro ejemplo es la frase "el que calla otorga", que ocurre mucho en los comentarios: "si fuera verdad, hubiera hecho la denuncia, ¿para qué se calló tanto tiempo? Seguro es mentira". (Disponible en https://articulos.elmeme.me/. Consultado 5 marzo 2018)

Como se puede observar, muchas falacias presentan funcionamientos semejantes a la posverdad, y aunque la autora ejemplifica con el discurso político, ellas están presentes en muchos otros tipos de discurso. Del mismo modo, las fronteras entre las falacias y las mentiras son bastante fluidas, difusas, y los sentidos de las dos categorías 
tienen que ver con los campos que las utilizan: falacias en el campo filosófico, mentiras en el campo socio-político.

En relación a la mentira, lo más interesante, contundente e ineludible es la mentira política y su complejo funcionamiento. Mucho se ha trabajado sobre este tipo de mentira, porque constituye un fenómeno ligado a lo político en el sentido restringido y amplio. El sujeto político está atrapado, sin salida, por la mentira. Como ejemplos emblemáticos, podemos mencionar los discursos políticos de campaña electoral que están plagados de mentiras, así como los otros subtipos de discurso político como los informes presidenciales, porque un componente estratégico de estos son las promesas que nunca suelen cumplirse, y los resultados que se presentan totalmente maquillados por la posverdad. En esta relación entre los sujetos políticos y los sujetos electores, hay una especie de convenio subterráneo, implícito en la circulación de las mentiras presentes en los ámbitos de la posverdad. De tal modo que asistimos a un fenómeno peculiar de lo político, que implica que la verdad no puede ser la estrategia de la eficacia, sino la mentira, o lo verosímil, que es el funcionamiento del parecer, no del ser. En estas reflexiones, no podemos dejar de mencionar que, de modo paradójico, los que buscan usar la verdad pierden terreno, para los que manipulan con lo falso, con la posverdad, fenómeno complejo muy peocupante de esta sociedad hiperconectada, que no se preocupa en vivir en la hiperrealidad. En efecto, aunque cuando siempre ha existido relacionada con el poder y por supuesto con la alienación, en estos últimos años con mucho mayor fuerza y presencia la posverdad se instaura como un personaje novedoso, maquillado, que oculta los innumerables vicios que funcionan de manera negativa en los procesos socio-histórico-político-culturales.

\section{LA POSVERDAD: ENCRUCIJADAS DE SENTIDOS CONFUSOS, AMBIGUOS, PERVERSOS. RETROCESO DEL PENSAMIENTO CRÍTICO}

En este apartado, retomamos la posverdad porque es el núcleo básico de reflexión del artículo, para relacionarla con lo político y con la ética, pero también con otros campos en donde está presente, como hemos mencionado. Lo político es entendido como una materialidad constitutiva de todas prácticas semiótico-discursivas, de distintas maneras y en diferentes grados. Lo ético entendido como los valores universales del ser humano, está casi siempre ausente cuando se relaciona con lo político y con otros tipos de procesos sociales, como el de los derechos humanos, que suelen trabajan con falacias y posverdades, porque no se cumplen las premisas fundamentales de la ética con los seres humanos.

Retomando a Nun (2017), la categoría de posverdad remite al fenómeno de que los hechos objetivos influyen e importan menos en la opinión pública, que las apelaciones a la emoción, dimensión fundamental en la subjetividad. Para este autor, los promotores del BREXIT tuvieron éxito porque confirmaron los prejuicios negativos de muchos ingleses sobre la Unión Europea, al plantear que superarían la crisis al salir de esta instancia; falsedad que solo se reconoció públicamente cuando se ganó el referendum. Siguiendo con Nun (2017), la sociedad del conocimiento, paradójicamente, logra el desarrollo impresionante del conocimiento, pero al mismo tiempo las redes sociales se convierten en un arquitecto perverso que construye falsedades, fabulaciones para anular el pensamiento y peor el pensamiento crítico. En otras 
palabras, se colapsa el conocimiento, se profundiza la pérdida de valores con la crisis de las incertidumbres de los seres humanos a fines del Siglo XX, y que continúan hasta la actualidad.

Para Chalamanch (2017), el neologismo 'posverdad' o 'verdad emotiva' permite describir una forma actual de crear y modelar la opinión pública, porque no importan los acontecimientos, ya que como mencionamos los hechos objetivos tienen menos capacidad de influencia que la apelación a las emociones, por lo cual el debate en política se orienta a apelar a las emociones desconectadas de los hechos, la verdad cediendo el espacio, el escenario a la posverdad. Con la posverdad, a nuestro juicio, ocurre el fenómeno raro de que la apariencia de verdad logra ser más eficaz que la propia verdad, estableciéndose una auténtica paradoja, ya mencionada, que se presenta cuando la verdad tiene que retirarse y ocultarse frente a la avalancha de las posverdades. Este fenómeno paradójico no encuentra todavía explicaciones convincentes, sino solo incompletas, o parciales. Algunos intentos de explicaciones recurren a las estrategias de persuasión eficaces utilizadas por los medios digitales, así como a la profunda crisis de valores de fines del siglo XX, que continúa hasta este siglo, todavía sin escenarios alternativos. Los sujetos atrapados por la posverdad no logran romper las burbujas de la posverdad, no logran cuestionar las noticias falsas que producen cárceles simbólicas de donde no pueden salir, ilustrando de manera concreta el mayor grado de alienación y de fetichismo de la consciencia. En el diagrama de las ataduras subjetivas, podemos observar las redes que atrapan a los sujetos.

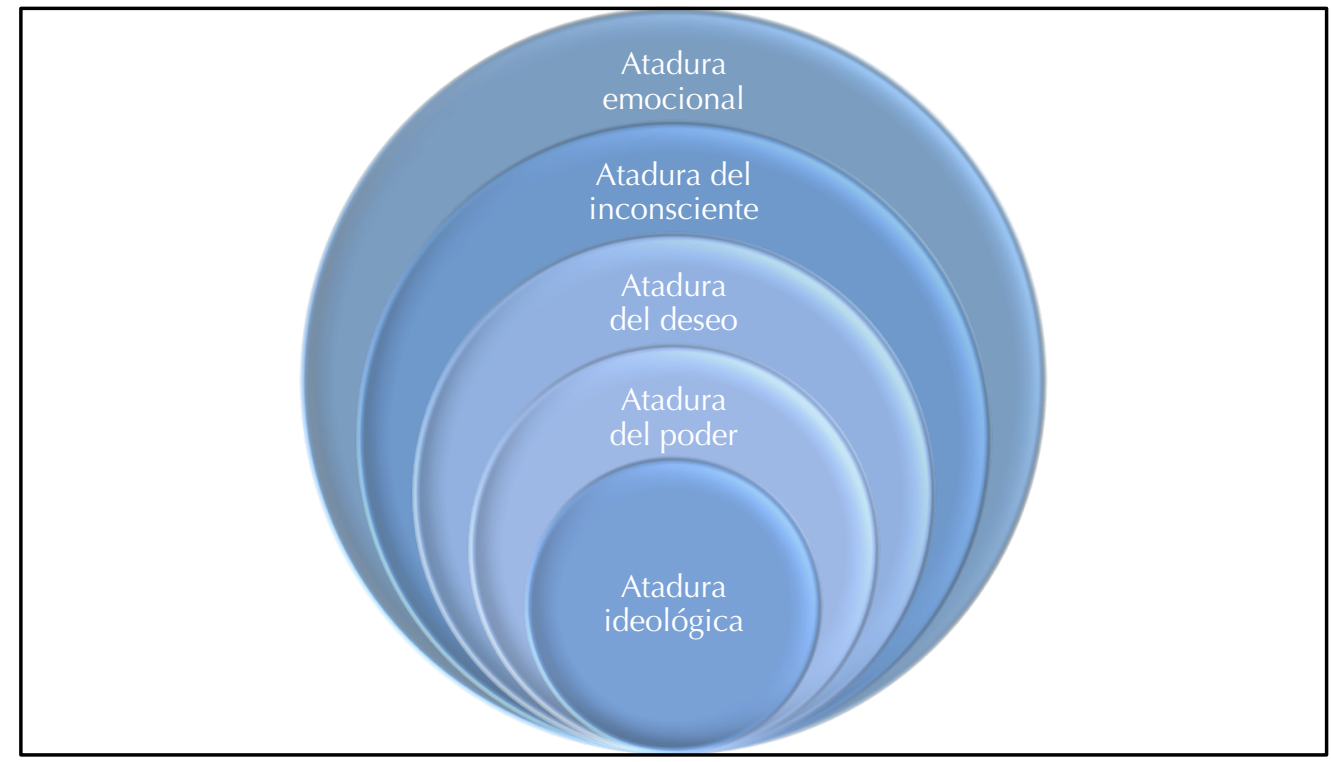

Gráfico 1: Ataduras subjetivas (elaboración propia).

La posverdad, para Nigro Moser (2017), puede ser abordada desde diferentes puntos de vista, desde la Nueva Retórica de Perelman, hasta otros campos cognitivos, como la psicología. La autora cita a Arturo Torres cuando éste afirma que la posverdad funciona porque no les interesa a los sujetos si los hechos son verdaderos o falsos, cediendo la objetividad el paso a las opiniones, a las creencias, a los prejuicios. Otros 
elementos que añade la autora, se refieren a los hechos alternativos, a las noticias falsas que se sostienen en una credibilidad anclada en los medios de comunicación con todas las estrategias que utilizan para cooptar, persuadir la audiencia. Sin duda, existe toda una maquinaria para lograr que los sujetos confíen en lo que leen, escuchan, o ven sin cuestionarse. Pero, a nuestro juicio, se debe establecer otra pregunta, de mayor problemática analítica: ¿por qué no les interesa a los sujetos actuales, a los ciberantropos saber si los hechos son verdaderos o falsos?, lo que realmente constituye una problemática que todavía no puede ser contestada a cabalidad.

Si retomamos a Baudrillard (1978), podemos constatar que la hiperrealidad vence a la realidad, a los distintos tipos de realidad, haciendo que los sujetos solo logren vivir en los imaginarios creados por las redes sociales, por los medios digitales, que son de amplio acceso a partir del uso masivo del celular, prótesis cerebral (Bartra 2007) que condensa en sí la contradicción desde la complejidad: tan constructivo y tan destructivo al mismo tiempo. La hiperrealidad supera y se pone en el lugar de la realidad, produciendo otras dimensiones sensoriales y perceptivas que alejan a los sujetos del pensamiento crítico y autocrítico y los instalan en prácticas falsas, inciertas, alienantes en donde buscan la catarsis en las posverdades, para los callejones sin salida de la historia contemporánea, prefiriendo vivir en los horizontes imaginarios.

Un problema interesante es el que ocurre con los sujetos en relación a la verdad y a la mentira, que se produce en las relaciones intersubjetivas. Los sujetos por el funcionamiento narcisista no están preparados, no aceptan la verdad en la vida cotidiana, menos en la pública. Cuando un intelectual es criticado, en general no acepta la crítica, no reflexiona y casi siempre se pone en la defensiva. En la relación a la verdad, que puede producirse en lo intersubjetivo, entre personas o entre grupos, es muy difícil utilizarla porque hay siempre resistencia en aceptar la crítica. En consecuencia, los sujetos no pueden usar la verdad en muchos ámbitos porque si lo hacen generan la violencia simbólica, los conflictos, las tensiones, las polémicas. Estas resistencias a la verdad, son resultantes de las fuertes cadenas subjetivas, como son el poder, la ideología, el deseo, el inconsciente, lo emocional, lo digital, que sin duda implican desafíos muy complejos para las subjetividades del mundo contemporáneo, para los sujetos. A nuestro juicio, estos no pueden oír las verdades en relación con las críticas de diversos tipos y solo lo logran hacer si realizan una reflexión continua, una lucha continua con el núcleo narcisista de los sujetos (Haidar 2006; Haidar s/f).

En sus investigaciones, Muñoz Sanhueza (2017) aporta muchos elementos para profundizar en algunos aspectos ya trabajados sobre la posverdad. En primer lugar, la autora destaca más la emoción que la razón en la eficacia de la época de la posverdad, a lo que se añade la inmediatez de la noticia, que impide cuestionarla o averiguar su validez, y a la cantidad asombrosa de noticias que sumergen a los sujetos en los laberintos de las posverdades. Otro aspecto importante que analiza es la estrategia de Facebook, al implementar los 'filter bubbles', burbujas de filtro que penetran con algoritmos y cierran la información que a los sujetos les gusta escuchar, leer, ver (2017: 45-46), excluyendo y jerarquizando la información. Esta técnica de las burbujas de filtro funciona de manera asombrosa no solo para la posverdad, sino para 
todas las áreas de lo digital que los usuarios utilizan. Las burbujas de filtro producen la desinformación y encadenan a los sujetos en burbujas que dan credibilidad a las falsedades, las viralizan. En efecto, las burbujas de filtro son uno de los soportes más fuertes para la circulación y recepción de las noticias falsas basadas en el sensacionalismo y en el espectáculo.

Considerando los dos procesos, el de BREXIT y de la candidatura de Donald Trump, esta autora plantea que la posverdad cambió la forma de hacer política en el mundo, por varias razones, entre las cuales se destacan: a) la profunda crisis de credibilidad en todo el mundo; b) las redes sociales que lograron presentarse como las portadoras de informaciones auténticas; c) la radicalización del populismo; d) la estrategia de usar la mentira, noticias falsas que las redes sociales se encargaron de difundir de manera rápida, ilimitada y continua, y e) el uso de estrategias emotivas, no racionales. En la dimensión emotiva, es donde residen las creencias, los prejuicios, a los cuales se apelaron para cooptar al electorado, más que a promesas posibles, o estrategias analíticas.

\section{EJEMPLOS DE POSVERDAD EN VARIOS CAMPOS}

Retomando lo que hemos planteado, la posverdad siempre ha existido en el campo semántico de la mentira, de lo falso, de las falacias, aunque en las coyunturas actuales se recurra a otras estrategias más potentes por la eficacia producida en las redes sociales y la manipulación de las grandes plataformas, como Facebook. En consecuencia, también es una posverdad considerar que este funcionamiento alienante se inicia en años más recientes, cuando en realidad estuvo, está y estará siempre presente en los funcionamientos del poder desde tiempos milenarios.

Fuera de la política, encontramos el trabajo de Nogues (2017) que investiga sobre el cambio climático y las falsas controversias generadas por los intereses del poder, así como el impacto de este grave problema para la sobrevivencia de la humanidad. La autora analiza la paradoja de que el conocimiento científico pierde su lugar, su validez que pasan a tener las opiniones falsas que difunden los medios digitales, las redes sociales. Desde esta perspectiva, los análisis de los científicos sobre los factores del cambio climático, y sus graves consecuencias no son eficaces y lo que queda circulando son opiniones derivadas de las posverdades, sin el soporte de las investigaciones científicas, que tienen la verdad.

La existencia y el origen del cambio climático es una evidencia científica, investigada, probada, pero lo que no se explica es por qué la postura que circula como válida es la que niega el cambio climático. Para la autora, tal postura se defiende desde grandes empresas petroleras, o industrias que usan combustible fósiles que contribuyen al cambio climático, lo cual es negado por los medios masivos que generan la posverdad de que es una energía limpia, y ponen en duda el cambio climático. Lo que observamos es la emergencia de muchas posverdades sobre este grave problema, que todavía no está atacado y considerado con suficiencia por los grandes países dominantes del mundo, lo que se explica por intereses económico-políticos.

En lo político, destacamos un ejemplo emblemático contemporáneo, relacionado con el desagravio que hace la OEA a la República Dominicana, en 2016 por el apoyo 
que este organismo dio a la invasión de los marines estadounidenses a este país, en 1965, con la manipulación de las posverdades de que el gobierno de Juan Bosch era comunista, que era una nueva Cuba, entre otras noticias falsas. En el Diario Libre, de República Dominicana, el día 16 junio de 2016, aparece el siguiente titular: 'La OEA emite declaración de desagravio por la invasión de abril de 1965', noticia de la cual presentamos algunos fragmentos muy importantes históricamente:

SANTO DOMINGO. La Asamblea General del Cuadragésimo Sexto Período Ordinario de Sesiones de la Organización de Estados Americanos (OEA), aprobó ayer a unanimidad por los 34 miembros, una declaración de desagravio a la República Dominicana por el rol desempeñado por el organismo regional, al dar el aval que permitió la intervención militar en el país en abril de 1965.

La Declaración de Desagravio, aprobada con el número AG/CG/ 7/16, está compuesta por tres puntos: primero se lamenta la pérdida de vidas humanas, y expresa las condolencias de la organización al pueblo dominicano; segundo, desagravia al pueblo dominicano por las acciones de abril de 1965 que interrumpieron el proceso de restablecimiento del orden constitucional en la República Dominicana, y tercero, reafirma los principios del derecho internacional, de la Carta de las Naciones Unidas y de la Carta de la OEA.

La Declaración del organismo multilateral fue emitida durante la celebración de la cuarta sesión plenaria de la OEA, llevada a cabo en el recién inaugurado centro de convenciones de la Cancillería.

Al respecto, el ministro de Relaciones Exteriores y Movilidad Humana de Ecuador, Guillaume Long, pidió también perdón a la República Dominicana por haber apoyado en 1965 la resolución de la OEA que avaló la intervención norteamericana, lo que costó muchas vidas y la violación de la soberanía del país.

Del otro lado, la secretaria adjunta del Departamento de Estado para Asuntos del Hemisferio, Mari Carmen Aponte, estimó innecesario recordar aquel momento histórico en el que 42, 000 soldados e infantes de marina estadounidenses invadieron el territorio dominicano dejando un saldo de muertes que algunos historiadores sitúan en 5,000, en su mayoría civiles.

"Es bien importante que no nos concentremos en el pasado. Mire, de las situaciones más difíciles siempre sale algo positivo y constructivo", respondió Aponte, ante el cuestionamiento de un periodista sobre si Estados Unidos pediría perdón al pueblo dominicano, tal y como Alemania hizo lo propio con el pueblo judío. (Disponible en: https://www.diariolibre.com/noticias/politica/la-oea-emite-declaracion-de-desagravio-porla-invasion-de-abril-de-1965-MX4044248. Consultado el 20 de febrero 2018).

Como se puede observar, este agravio está en un discurso político-histórico emblemático, porque un organismo como la OEA se disculpa públicamente, a nivel internacional por la invasión que apoyó a República Dominicana de los Estados Unidos, en 1965. Sobre este lamentable acontecimiento, recurrimos a los planteamientos del presidente derrocado Juan Bosch, quien en el libro Viaje a los 
Antípodas (1980), hace varios planteamientos denunciando las posverdades que utiliza Estados Unidos

Fui a Asia y al Sudeste Asiático a buscar la Verdad. [...] Yo oí al presidente de los Estados Unidos, país líder de la tal democracia representativa, mentir como sólo mienten los seres más abyectos; oí a él y senadores, diputados, altos personajes y a la radio oficial de los Estados unidos acusar a la revolución democrática del pueblo dominicano de criminal y salvaje... (1980: 39-40)

Así, a partir del 28 de abril de 1965 comencé a estudiar cuidadosamente la historia de Estados Unidos tal como es y no como la cuentan los norteamericanos; comencé a darme cuenta de que ese país gigantesco y poderoso tiene una antigua tradición de engaños y una capacidad asombrosa para mentirle al mundo; ha hallado la forma de atropellar de la manera más brutal a los pueblos débiles y presentar esos atropellos como si fueran grandes y costosos esfuerzos para liberarlos de males infernales y para defender la libertad humana (1980: 40)

Allí, en Yugoslavia y Rumania comprobé que de cada mil palabras sobre los países socialistas que se escriben en los Estados Unidos, novecientas noveintinueve son mentiras (1980:41).

En otras palabras, se confirma que con la categoría de posverdad no hay nada nuevo bajo el sol, porque en la historia de los imperios está siempre presente la posverdad de distintas maneras, en diferentes grados, pero siempre funcionando para la dominación y cooptación de los sujetos.

Otro ejemplo del uso impactante de la posverdad, es la invasión a Irak con el argumento falaz de la construcción de armas de destrucción masiva. En un artículo de Tele Sur, escrito por David Swanson, publicado en 16 de julio de 2015, con el título "Documento Secreto Muestra Reacción de la CIA al No Encontrar Armas de Destrucción Masiva en Irak", se afirma que en esta invasión el Gobierno de Estados Unidos invadió Irak, devastó toda una sociedad, mató a más de un millón de personas, hirió, traumatizó y desplazó a millones más. Y se añade que después de que Duelfer, encargado de pesquisar sobre las armas, con 1.700 miembros del ejército de Estados Unidos, afirmara que no encontró ninguno de los supuestos arsenales de armas de destrucción masiva, de nada sirvió porque $42 \%$ de los estadounidenses (y el 51 por ciento de los republicanos) todavía creen lo contrario. (Disponible en : https://www.telesurtv.net/opinion/Documento-Secreto-Muestra-Reaccion-de-la-CIA-al-No-Encontrar-Armas-de-Destruccion-Masiva-en-Irak-20150716-0029.html. Consultado el 28 febrero 2018)

En otro artículo de La Nación, publicado el 10 de septiembre de 2005, intitulado "Powell se arrepintió del discurso que dio en la ONU sobre Irak", el exsecretario de Estado norteamericano, confiesa lo siguiente:

"Es una mancha, porque yo fui quien hice esa presentación en nombre de Estados Unidos ante el mundo, y eso será siempre parte de mi carrera", dijo Powell, en una entrevista concedida a la periodista Barbara Walters, de la cadena de televisión ABC..." Había algunas personas en la comunidad de inteligencia que sabían en ese momento que algunas de las 
fuentes no eran buenas, y que no debían ser consideradas. Pero no hablaron y eso me devastó", señaló. (Disponbile en: https://www.lanacion.com.ar/737624-powell-se-arrepintio-del-discurso-que-dio-en-la-onu-sobre-irak (Consultado el 28 febrero 2018).

Esta posverdad por la cual nunca pasó la ética tuvo gran eficacia y el arrepentimiento del Powell no sirvió para nada, porqué aunque murieran un millón de personas, y aunque oficialmente se niega la existencia de las armas de destrucción masiva, buena parte del pueblo norteamericano siguió creyendo, envuelto por las burbujas de mentira, esclavizados por la posverdad.

Los ejemplos son innumerables, más bien lo que no se encuentran son prácticas semiótico-discursivas que logren escapar de las posverdades. Recurrimos a un último ejemplo, el terremoto de México en septiembre de 2017 que fue motivo para la producción de innumerables posverdades, es decir, de mentiras. Más allá de todo el sensacionalismo, del espectáculo en que los medios masivos convirtieron el terremoto mexicano, de todas las posverdades generadas en relación a las áreas afectadas como fueron el estado de Oaxaca, Chiapas, Puebla se destaca la más infame construcción de posverdad, con la historia construida sobre Frida Sofia: la niña que los medios transmitieron durante todo el día 21 de septiembre de 2017, que estaba atrapada en las ruinas del Colegio Enrique Rebsamen. Los medios dramatizaron y decían que los topos habían conversado con Frida, quien les pedía alimento y auxilio. Pero, después de que la noticia se virilizara, no se pudo sostener y vino la verdad: no existía tal niña. No se pudo sostener esta mentira/posverdad, porque en la lista de alumnos no existía tal nombre, no vinieron los padres a reclamarla, y la directora no pudo aclarar nada. Frente a la realidad de que no existía tal niña, no se pudo sostener esta posverdad y vence la verdad, lo que ocurre pocas veces. (Disponible en: www.bbc.com/mundo/noticias-america-latina-41363083; http://www.proceso.com.mx/504440/caso-fridasofia-una-verguenza-gobierno-pena-nieto-wp; https://www.elespanol.com/mundo/america/20170921/248476143 0.html. (Consultado el 28 febrero 2018)

\section{ALGUNAS CONCLUSIONES}

Si partimos de la premisa de que la mentira, la falsedad, la posverdad siempre existieron en lo privado, en lo público, en las esferas de lo político, en otras áreas como de los medios masivos y de las mismas ciencias, es importante preguntarse porque en estos momentos, surge la categoría de posverdad, con tintes positivos escondiendo toda la oscuridad que contiene. Es decir, las esferas interconectadas de la falsedad, la mentira, la posverdad siempre han existido en mayor o menor grado en todas las culturas, en todo el desarrollo histórico de la humanidad. Sin embargo, la característica novedosa es que se impone por las redes sociales, por el Diccionario de Oxford que integra el concepto de posverdad con nuevos sentidos que procuran opacar lo negativo, la ausencia total de la ética en los procesos que se generan y que inundan las conciencias.

En la amplia literatura sobre la posverdad, se menciona que su aceptación colectiva internacional se debe al aumento de la crisis de credibilidad, a la manipulación digital y todas las estrategias de las redes sociales, a la capacidad ilimitada de éstas para circular todo lo falso, para crear opinión y adhesiones, al 
bombardeo incesante de noticias falsas en todos los ámbitos y al uso sin ninguna ética de los medios digitales. En otras palabras, se juntan la crisis de la credibilidad, la crisis de los valores, la ausencia de horizontes positivos y el desarrollo de los medios digitales que utilizan todas las estrategias comunicativas posibles para producir y reproducir de modo incesante, incontrolable las burbujas de la posverdad, con las cuales enclaustran y subordinan a los sujetos.

Pero, frente a esta problemática situación de una profunda alienación de los sujetos, surgen cuestiones que todavía no podemos responder. Una de ellas es que, frente a la crisis de credibilidad, a la crisis de valores, los sujetos no logran tener un pensamiento crítico, sino que se ahogan en la alienación total, y pasan la credibilidad a la posverdad, al ámbito contrario a la verdad. Paradoja profunda del mundo actual, que nos lleva a preguntar ipor qué las noticias falsas logran tener mayor o total credibilidad sobre las noticias verdaderas? En otras palabras, ¿en el escenario público por qué la verdad se colapsa y sale victoriosa la posverdad? Estas constituyen preguntas muy complejas, que necesitan estudios desde la complejidad y la transdisciplina, porque los análisis que se presentan de las apelaciones a la dimensión emocional, a las creencias y prejuicios, a las estrategias digitales de las burbujas de filtro, explican solo en una pequeña parte estos fenómenos.

La preocupación e inquietud que se presenta es que los sujetos, desde finales del siglo pasado, hasta estos momentos, prefieren quedar envueltos en estas burbujas de mentira, que opacan la realidad, los hechos objetivos. Lo que se ha producido por la globalización, que difunde las crisis de todos tipos es que los sujetos queden atrapados, encadenados, pero incrustados en una tranquilidad y felicidad del simulacro, de la hiperrealidad. Las cadenas subjetivas, ya mencionadas, generan desafíos muy profundos para los sujetos complejos del mundo contemporáneo.

En síntesis, más allá de la categoría de posverdad quedan muchos desafíos para los seres humanos superar, como el de lograr salir de las burbujas de mentiras, para producir un pensamiento crítico, con ética, con los valores que logren vencer los poderes perversos de los medios digitales esclavizadores, que se propagan en las fronteras cronotópicas, espaciotemporales, sin límites. En este abrumador torbellino creado por los medios digitales, los sujetos deben asumir el desafío de luchar por la verdad, por la ética en todas las dimensiones de la vida, buscando caminos alternativos al dominio de las redes sociales, de los medios digitales que envuelven a los seres humanos y los hacen entrar en laberintos de falsedades, sin salida, porque no encuentran los hilos de Ariadna (mito de Minotauro).

\section{BIBLIOGRAFIA}

Bajtín, Mijaíl (1989). Teoría y estética de la novela. Madrid: Taurus.

Baudrillard, Jean (1978), Cultura y Simulacro, Barcelona, Editorial Kairós

Buen Abad, Fernando (2017). Semiótica de las falacias: Ética entre la "Plus verdad" y la "Plus mentira", Tele Sur. Disponible en https://www.telesurtv.net/bloggers/Semiotica-de-las-falacias-Etica-entre-la-Pos-verdad-y-la-Plus-mentira-20170704-0007.html. (Consultado en 26 febrero 2017) 
Bartra, Roger (2007). Antropologia del Cerebro. Las conciencias y los sistemas simbólicos, México, Fondo de Cultura Económica.

Bosch, Juan (1980). Viaje a los Antípodas, Santo Domingo, Editora Alfa y Omega

Chalamanch, Marc (2017). "Foucault - Trump: preludio de la posverdad." En Urban

Living Lab. (Disponible en: http://www.urbanlivinglab.net/posverdad/. Consultado el 20 noviembre 2017)

Foucault, M. (1980). El Orden del discurso, Barcelona, Tusquets Editores.

— (1993). Microfísica del poder. Madrid, Ediciones La Piqueta.

Haidar, Julieta (s/f). "Las ciencias de la emoción desde la complejidad y la transdisciplina". En: Fronteras semióticas de la emoción. Los procesos del sentido en las culturas. En prensa.

- (2006). Debate CEU-Rectoría. Torbellino Pasional de los Argumentos. México, Universidad Nacional Autónoma de México.

- (1990). Discurso Sindical y Procesos de Fetichización. Proletariado textil poblano de 1960 a 1970. México, Instituto Nacional de Antropología e Historia.

Hamblin, C.L., (1970). Fallacies. Vancouver, Vale Press.

Mignolo, Walter (2005). El pensamiento des-colonial, desprendimiento y apertura: un manifiesto. España, Tristes Trópicos. Disponible en: https://edisciplinas.usp.br/pluginfile.php/146654/mod resource/content/1/WalterMignolo. (Consultado el 15 marzo 2018)

Muñoz Sanhueza, Priscilla (2017) Medios de comunicación y posverdad: análisis de las noticias falsas en las elecciones presidenciales de EEUU de 2016. Barcelona, Universitat Autónoma de Barcelona. Disponible en: https://ddd.uab.cat/pub/trerecpro/2017/hdl_2072_293813/tfm_priscilla_munoz.pdf. (Consultado en noviembre 2017)

Nicolas, Juan A.y Frápolli, Maria J (1997). "Teorías de la Verdad". En Diálogo Filosófico, № 38, pp. 148 - 178, Madrid, Editorial Diálogo Filosófico. Disponible en: http://www.ugr.es/ frapolli/teoriasactuales.pdf. (Consultado en 26 febrero 2017)

Nigro Moser, Patricia, 2017, «Posverdad y Comunicación Política. Una aproximación desde la Nueva Retórica». Disponible en: (https://www.researchgate.net/publication/318430652_I_FORO_ACADEMICO_INTERNACIONAL_DE_COMUNICACIO N POLITICA LATINOAMERICANA ABOCCS 6 de abril de 2017. (Consultado el 28 febrero 2018)

Nogués, Guadalupe (2017) "El cambio climático y la posverdad". Publicado el 28 agosto, Blog ¿Cómo Sabemos? ¿Cómo sabemos lo que sabemos? Disponible en: https://comosabemos.com/2017/08/28/el-cambio-climatico-y-la-posverdad/.

(Consultado,el 20 noviembre 2017)

Nun, José (2017). "La posverdad marca el fin de una época". En La Nación, Artículo de opinión. Disponible en: https://www.lanacion.com.ar/1988503-la-posverdadmarca-el-fin-de-una-epoca. (Consultado el 28 febrero 2017) 
Rivera Cusicanqui, Silvia (2010). Ch'ixinakax utxiwa: una reflexión sobre prácticas y discursos descolonizadores - 1a ed. Buenos Aires, Tinta Limón.

Santiago Castro-Gómez y Ramón Grosfoguel, Editores (2007). El giro decolonial: reflexiones para una diversidad epistémica más allá del capitalismo global. Bogotá, Siglo del Hombre Editores; Universidad Central, Instituto de Estudios Sociales Contemporáneos y Pontificia Universidad Javeriana, Instituto Pensar.

van Eemeren, Franz H \& Rob Grootendorst (1987). Fallacies in Pragma-Dialectical Perspective. En Argumentation 1.2: 283-301. 